\title{
Agreement of body adiposity index (BAI) and paediatric body adiposity index (BAlp) in determining body fat in Brazilian children and adolescents
}

\author{
Mariana De Santis Filgueiras ${ }^{1, *}$, Roberta Stofeles Cecon $^{2}$, Eliane Rodrigues de Faria ${ }^{3}$, \\ Franciane Rocha de Faria ${ }^{4}$, Patrícia Feliciano Pereira ${ }^{1}$, Andréia Queiroz Ribeiro ${ }^{1}$, Silvia \\ Eloiza Priore ${ }^{1}$ and Juliana Farias de Novaes ${ }^{1}$ \\ 'Department of Nutrition and Health, Biological Sciences Center, Federal University of Viçosa, CEP 36570-900, \\ Viçosa, MG, Brazil: ${ }^{2}$ Collegiate of Medicine, Federal University of Vale do São Francisco, Paulo Afonso, BA, Brazil: \\ ${ }^{3}$ Department of Nutrition, Biological Sciences Institute, Federal University of Juiz de Fora, Juiz de Fora, MG, Brazil: \\ ${ }^{4}$ Department of Medicine, Exact and Natural Science Institute, Federal University of Mato Grosso, Rondonópolis, MT, \\ Brazil
}

Submitted 9 December 2017: Final revision received 15 May 2018: Accepted 21 August 2018: First published online 12 October 2018

\begin{abstract}
Objective: To evaluate agreement of the body adiposity index (BAI) and paediatric body adiposity index (BAIp) in estimating body fat compared with dual-energy X-ray absorptiometry (DXA) and to propose cut-off points for these indices to classify excess adiposity in Brazilian children and adolescents.

Design: Cross-sectional study. Measures of weight, height, hip circumference, BMI and body fat percentage (\%BF) assessed by DXA were taken, and BAI and BAIp were calculated. The Bland-Altman plot was used to estimate agreement between the methods, and the receiver-operating characteristic curve to determine the cutoff points for BAI and BAIp per age and sex in comparison with DXA.

Setting: Viçosa, Minas Gerais, Brazil.

Subjects: Children and adolescents aged 8-19 years ( $n$ 1049).

Results: Of the children and adolescents, 52.4\% were girls. BAI and BAIp had satisfactory performance by the receiver-operating characteristic curve, except for the 18-19 years age group, whose BAIp had better predictive capacity than BAI. The agreement analysis showed that BAI overestimated $\%$ BF by $2.64 \%$, on average, using DXA; while BAIp underestimated $\%$ BF by $3 \cdot 37 \%$.

Conclusions: BAI and BAIp showed low agreement with the body fat obtained by DXA, requiring caution when interpreting body composition data in children and adolescents.

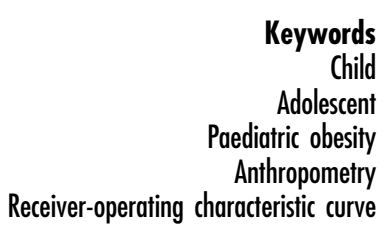

Puberty is defined as the physiological process of hormonal maturation and somatic growth. It can manifest itself in different forms and at different periods for every individual due to hormonal, genetic and environmental influences ${ }^{(1,2)}$. Normally the onset of puberty, with hormonal and body changes, occurs between the ages of 8 and 13 years in girls and between 9.6 and 13.6 years in boys, thus comprising the end of childhood and the beginning of adolescence in both sexes. In addition, this is a period involving physical, psychological and social changes among girls and boys, along with changes in body composition ${ }^{(1,2)}$.

The maturation process causes changes in body composition and differences between sexes, in which boys have a higher proportion of fat-free mass and girls a greater amount of fat mass ${ }^{(1)}$. Therefore, the correct estimation of body composition is important in the evaluation and monitoring of the health and nutritional status of children and adolescents, considering the relationship between CVD, diabetes mellitus, dyslipidaemias, hypertension and metabolic syndrome ${ }^{(3,4)}$, which usually remain in adult life ${ }^{(5)}$.

Increased prevalence of obesity and metabolic changes have been reported in all age groups. According to the Brazilian Institute of Geography and Statistics, based on data from the Consumer Expenditure Survey (POF) conducted during 2008-2009, the prevalence of overweight and obesity in children aged 5-9 years was 33.8 and $14.2 \%$, respectively, and overweight was present in $20.6 \%$ and obesity in $5.0 \%$ of adolescents ${ }^{(6)}$. 
Different methods exist for assessing body composition. Among the low-cost methods, BMI has been the most criticized in recent years for not analysing the components of body composition, as has skinfold thickness for its applicability and reliability ${ }^{(7)}$.

Because of these difficulties in nutritional assessment, Bergman et $a l .{ }^{(8)}$ proposed the body adiposity index (BAI) for adult subjects, a new parameter to evaluate body composition from two anthropometric measures, both of which are easily reproducible: height, in metres, and hip circumference, in centimetres. It is a simple, fast, relatively inexpensive and non-invasive method. In 2013, the paediatric body adiposity index (BAIp) ${ }^{(9)}$ was also proposed to predict body fat in children and adolescents aged 5-12 years because the BAI, initially used for adults, overestimates body fat in the paediatric population ${ }^{(10)}$. BAI has been widely used for adults ${ }^{(7,8,11)}$; whereas BAIp has still been scarcely used and no studies have been found which compare the use of BAI and BAIp in the evaluation of body composition with dual-energy X-ray absorptiometry (DXA) in Brazilian children and adolescents.

Thus, in view of the importance of body composition evaluation in clinical practice and population studies, the present study aimed to evaluate the agreement of BAI and BAIp compared with DXA and to propose cut-off points for these indices aiming at classification of excess body adiposity in Brazilian children and adolescents, by age and sex.

\section{Methods}

\section{Population and study design}

The present study was of cross-sectional design and carried out with children and adolescents, between 8 and 19 years of age, enrolled in public and private schools in the urban and rural area of Viçosa, Minas Gerais, Brazil. This municipality is located in the Zona da Mata Region at $227 \mathrm{~km}$ from the capital, Belo Horizonte. According to the 2010 Census, Viçosa has a land area of $299 \mathrm{~km}^{2}$ and 72244 inhabitants, of whom $93.2 \%$ live in urban areas. The gross domestic product per capita in Viçosa is $\mathrm{R} \$ 7704 \cdot 50^{(12)}$.

The 8- and 9-year-old participants of the present study were selected from the Survey of Health Assessment of Schoolchildren (Pesquisa de Avaliação da Saúde do Escolar - PASE), a cross-sectional study carried out to evaluate the cardiovascular health of children enrolled in urban schools of Viçosa, Minas Gerais, Brazil. The statistical program Epi Info (version 7) was used for sample calculation, considering the total number of children aged 8 and 9 years enrolled in urban schools in 2015 ( $n$ 1464), prevalence of obesity of $10 \cdot 7 \%^{(13)}$, tolerated error of $3 \%$, confidence level at $95 \%$ and $20 \%$ increase to cover losses, totalling 392 children in the final sample. The selection of children has already been described previously ${ }^{(14,15)}$. Briefly, stratified random sampling was carried out to select the schoolchildren, in which the number of children to be sampled in each school was weighted by school according to its size. Subsequently, a draw was carried out using a random number table to complete the number of students needed per school. After the selection, those responsible for children were contacted by telephone and invited to participate in the study. Parents or guardians who allowed the participation of their children in the study signed the Informed Consent Term, in accordance with the Declaration of Helsinki, and we started data collection at the Health Division of the Federal University of Viçosa. At the end of the data collection, loss of $4.2 \%$ was recorded because some children did not accomplish all stages of the study. The final sample consisted of 378 students.

Adolescents aged 10-19 years were selected from rural and urban public and private schools (fifth year of elementary school to third year of secondary education) of the municipality of Viçosa, Minas Gerais, Brazil. The sample size was calculated using the Epi Info program (version 6.04) using the specific formula for cross-sectional studies, considering the total adolescent population of 11898 from Viçosa ${ }^{(16)}$, with expected prevalence of outcome of $50 \%{ }^{(17)}$ (since the study considered multiple cardiovascular risk factors as outcome) and a tolerated error of $5 \%$, resulting in a minimum sample of 628 adolescents, at $99 \%$ confidence level. The sample consisted of 671 adolescents.

Adolescents were selected through the stratified random sampling process. The number of students to be sampled in each school was determined according to the sex, age and school size. The research was divulged in the classrooms of primary and secondary education, at which time the Inform Consent Term was made available to students. Subsequently, the consents signed by each adolescent and his/her parent/guardian, in the case of minors under 18 years, were collected by the research team on previously scheduled days. The draw of the adolescents was carried out using the table of random numbers, based on the list of students who gave their consent ${ }^{(18,19)}$.

Inclusion criteria were: no regular use of drugs that altered glycaemia, insulinaemia, lipid metabolism and/or blood pressure levels; no participation in weight-reduction and weight-control programmes; no physical, cognitive or multiple disabilities; no regular use of diuretics/laxatives; and for female adolescents, not being pregnant or having been previously pregnant.

Studies were approved by the Human Research Ethics Committee of the Federal University of Viçosa (case numbers 0140/2010 and 663.171/2014).

\section{Anthropometric assessment and body composition}

Anthropometric measures were taken in a suitable room by a trained examiner, with participants barefoot and wearing light clothes, using standardized international techniques ${ }^{(20)}$. Weight was measured on a digital electronic scale, with a capacity of $150 \mathrm{~kg}$ and accuracy of $0 \cdot 1 \mathrm{~kg}$. 
Height was measured using a stadiometer graduated in millimetres. Weight and height measurements were used to calculate BMI. Children's nutritional status was classified using the cut-off points of BMI-by-age, according to the WHO $Z$-score recommendation ${ }^{(21)}$.

Hip circumference was measured on the largest part of the gluteus, with an inelastic measuring tape with a $0 \cdot 1 \mathrm{~cm}$ precision, with participants standing, feet joined and body weight supported by both legs ${ }^{(20)}$.

Percentage of body fat (\%BF) was estimated by BAI, BAIp and DXA.

BAI was calculated from the hip circumference (in centimetres) and height (in metres), according to the equation of Bergman et al. ${ }^{(8)}$ :

$$
\mathrm{BAI}=\frac{\text { hip circumference }(\mathrm{cm})}{[\text { height }(\mathrm{m})]^{1.5}}-18 .
$$

BAIp was calculated with the equation ${ }^{(9)}$ :

$$
\text { BAIp }=\frac{\text { hip circumference }(\mathrm{cm})}{[\text { height }(\mathrm{m})]^{0 \cdot 8}}-38 .
$$

DXA (Lunar Prodigy Advance; GE Medical Systems Lunar, Milwaukee, WI, USA) was considered as the reference method; the evaluation was conducted by a specialized technician, using the device's software for body composition analysis. The participants remained supine on the table and rays were emitted and measured by an energydiscriminating detector. Participants also followed a laboratory protocol for the examination and wore light clothes without any metal ornament. The participants whose \%BF obtained by DXA was greater than or equal to the 85 th percentile, by age and sex in the sample, were considered to have excess body fat. Some studies with children and adolescents have shown that use of the 85th percentile is able to identify those with excess body fat ${ }^{(22,23)}$.

\section{Data analysis}

Statistical analysis was performed using the statistical software package IBM SPSS Statistics for Windows version 20.0 and MedCalc version 9.3, at 5\% significance level for all tests. Variables were evaluated for normality using the Kolmogorov-Smirnov test.
Descriptive analysis of data using estimates of relative frequencies and medians (interquartile range) was performed according to the nature of the variables. The Mann-Whitney test was used to compare the median \%BF obtained by BAI, BAIp and DXA in both sexes.

The areas under the receiver-operating characteristic curve determined the validity of BAI and BAIp in predicting total body fat excess using DXA. The receiveroperating characteristic curves were also used to identify BAI and BAIp cut-off points for the classification of excess body fat according to age and sex.

The contrasting groups method was used to evaluate if proposed cut-off points were able to identify excess android fat according to age and sex. This method is based on the interpretation of several computed statistical indices: (i) probability of correct decisions; (ii) misclassification of errors; (iii) validity coefficient; and (iv) utility analysis ${ }^{(24)}$.

The Bland-Altman plot method was used to evaluate the agreement of the estimates from each method tested in relation to DXA. The bias represents the mean difference between the two methods; agreement limits of $95 \%$ (SD multiplied by 1.96) were calculated from the SD of the mean difference. It is required that bias should be statistically equal to zero (paired $t$ test) for a method to be considered as having a good agreement, and it is important to consider agreement limits in the interpretation $^{(25,26)}$. To complement the analysis, we proceeded to perform linear regression to assess the occurrence of proportional bias, and values with statistical significance lower than $5 \%$ were considered as proportional bias.

\section{Results}

The study included 1049 children and adolescents (52.4\% girls), with median age of 11.2 years (interquartile range: $9 \cdot 4-15 \cdot 1$ years). In relation to sex, girls had a higher $\% \mathrm{BF}$ $(P<0.001)$ than boys, regardless of the evaluation method used (Table 1).

Table 2 shows the comparison between the performances of BAI and BAIp in identifying high adiposity. In general, both indicators showed satisfactory performance; however, in the 18-19 years age group, BAIp had a better predictive capacity compared with BAI.

Table $1 \mathrm{BMI}$ and percentage body fat (\%BF), by sex, estimated using different methods among children and adolescents aged 8-19 years

\begin{tabular}{|c|c|c|c|c|c|}
\hline \multirow[b]{2}{*}{ Method } & \multicolumn{2}{|c|}{ Girls } & \multicolumn{2}{|c|}{ Boys } & \multirow[b]{2}{*}{$P$ value } \\
\hline & Median & IQR & Median & IQR & \\
\hline $\mathrm{BMI}\left(\mathrm{kg} / \mathrm{m}^{2}\right)$ & $18 \cdot 6$ & $16 \cdot 3-21 \cdot 4$ & $17 \cdot 9$ & $16 \cdot 0-20 \cdot 6$ & 0.051 \\
\hline \%BF, DXA & $27 \cdot 0$ & $21 \cdot 0-33 \cdot 0$ & $16 \cdot 0$ & $11 \cdot 0-24 \cdot 2$ & $<0.001^{*}$ \\
\hline$\% \mathrm{BF}, \mathrm{BAI}$ & $26 \cdot 4$ & $24.1-29.5$ & 24.0 & $20 \cdot 9-26 \cdot 9$ & $<0.001$ \\
\hline$\%$ BF, BAlp & $20 \cdot 8$ & $16 \cdot 7-28 \cdot 8$ & $17 \cdot 1$ & $14 \cdot 4-21 \cdot 0$ & $<0.001^{\star}$ \\
\hline
\end{tabular}
(n 1049), Viçosa, Minas Gerais, Brazil, 2010-2012/2015

IQR, interquartile range; DXA, dual-energy X-ray absorptiometry; BAI, body adiposity index; BAlp, paediatric body adiposity index.

${ }^{*} P<0.05$ (Mann-Whitney test). 
Table 3 shows the cut-off points for BAI and BAIp to classify excess body fat according to age and sex. In girls, the BAI cut-off points ranged from $27 \cdot 6$ to $30 \cdot 7 \%$ and those of BAIp from 20.9 to $27 \cdot 8 \%$. In boys, the BAI cutoff points ranged from $21 \cdot 2$ to $30 \cdot 1 \%$ and BAIp cut-off points from $17 \cdot 4$ to $24.6 \%$. A summary of analytical steps of the contrasting groups methods showed that the proposed cut-off points were adequate to identify excess android fat, except for BAI in boys aged 18-19 years (Table 4).

The agreement analysis demonstrated that BAI overestimates, on average, the \%BF obtained by DXA by $2.64 \%$; while BAIp underestimates it by $3.37 \%$ on average (Fig. 1). The mean differences were statistically different from zero by the paired $t$ test (data not shown). The linear regression analysis showed that both indicators had proportional bias $(P<0.05)$; that is, using BAI and BAIp in children and adolescents with extreme values of body fat can lead to errors of overestimation and underestimation, respectively.

\section{Discussion}

The BAI and BAIp equations were developed to evaluate body composition and be an alternative to BMI in the diagnosis of overweight and obesity in individuals ${ }^{(8,27)}$. Therefore, studies to evaluate the performance and agreement of BAI and BAIp in predicting excess adiposity in different populations are important, since these indices are indirect methods developed to determine adiposity easily, using only hip circumference and height.

Table 2 Areas under the receiver-operating characteristic curve (AUC) of the body adiposity index (BAI) and the paediatric body adiposity index (BAlp) to identify high adiposity, by age and sex, in children and adolescents aged $8-19$ years ( $n$ 1049), Viçosa, Minas Gerais, Brazil, 2010-2012/2015

\begin{tabular}{|c|c|c|c|c|c|c|c|c|c|}
\hline \multirow[b]{2}{*}{ Variable } & \multicolumn{3}{|c|}{ Total } & \multicolumn{3}{|c|}{ Girls } & \multicolumn{3}{|c|}{ Boys } \\
\hline & AUC & $95 \% \mathrm{Cl}$ & $P$ value & AUC & $95 \% \mathrm{Cl}$ & $P$ value & AUC & $95 \% \mathrm{Cl}$ & $P$ value \\
\hline \multicolumn{10}{|l|}{ BAI } \\
\hline $8-9$ years & 0.944 & $0.915,0.965$ & $<0.001$ & 0.941 & $0.898,0.970$ & $<0.001$ & 0.946 & $0.902,0.974$ & $<0.001$ \\
\hline $10-11$ years & 0.926 & $0.833,0.957$ & $<0.001$ & 0.947 & $0.886,0.981$ & $<0.001$ & 0.932 & $0.867,0.971$ & $<0.001$ \\
\hline $12-13$ years & 0.955 & $0.901,0.984$ & $<0.001$ & 0.955 & $0.856,0.992$ & $<0.001$ & 0.973 & $0.902,0.996$ & $<0.001$ \\
\hline $14-15$ years & 0.899 & $0.828,0.948$ & $<0.001$ & 0.923 & $0.835,0.972$ & $<0.001$ & 0.994 & $0.900,1.000$ & $<0.001$ \\
\hline $16-17$ years & 0.895 & $0.814,0.949$ & $<0.001$ & 0.881 & $0.768,0.952$ & $<0.001$ & 1.000 & $0.902,1.000$ & $<0.001$ \\
\hline $18-19$ years & $0.823^{*}$ & $0.747,0.884$ & $<0.001$ & 0.923 & $0.831,0.974$ & $<0.001$ & 0.908 & $0.809,0.966$ & $<0.001$ \\
\hline \multicolumn{10}{|l|}{ BAlp } \\
\hline 8-9 years & 0.973 & $0.952,0.987$ & $<0.001$ & 0.968 & $0.932,0.987$ & $<0.001$ & 0.981 & $0.949,0.995$ & $<0.001$ \\
\hline $10-11$ years & 0.938 & $0.898,0.966$ & $<0.001$ & 0.962 & $0.907,0.989$ & $<0.001$ & 0.949 & $0.890,0.982$ & $<0.001$ \\
\hline $12-13$ years & 0.976 & $0.930,0.995$ & $<0.001$ & 0.953 & $0.853,0.992$ & $<0.001$ & 0.990 & $0.929,0.997$ & $<0.001$ \\
\hline $14-15$ years & 0.931 & $0.867,0.970$ & $<0.001$ & 0.954 & $0.877,0.989$ & $<0.001$ & 0.977 & $0.871,0.996$ & $<0.001$ \\
\hline $16-17$ years & 0.937 & $0.866,0.976$ & $<0.001$ & 0.907 & $0.800,0.967$ & $<0.001$ & 1.000 & $0.902,1.000$ & $<0.001$ \\
\hline $18-19$ years & $0.920^{*}$ & $0.860,0.961$ & $<0.001$ & 0.956 & $0.876,0.991$ & $<0.001$ & 0.957 & $0.873,0.991$ & $<0.001$ \\
\hline
\end{tabular}

${ }^{*} P<0.05$ ( $Z$ test $)$.

Table 3 Cut-off points, sensitivity (Sens.), specificity (Spec.), positive predictive value (PPV) and negative predictive value (NPV) of the body adiposity index (BAI) and the paediatric body adiposity index (BAlp) for the classification of high adiposity, by age and sex, in children and adolescents aged 8-19 years ( $n$ 1049), Viçosa, Minas Gerais, Brazil, 2010-2012/2015

\begin{tabular}{|c|c|c|c|c|c|c|c|c|c|c|c|c|c|c|}
\hline \multirow[b]{2}{*}{ Variable } & \multicolumn{7}{|c|}{ Girls } & \multicolumn{7}{|c|}{ Boys } \\
\hline & $\begin{array}{l}\text { Cut- } \\
\text { off } \\
\text { point }\end{array}$ & $\begin{array}{c}\text { Sens. } \\
(\%)\end{array}$ & $95 \% \mathrm{Cl}$ & $\begin{array}{c}\text { Spec. } \\
(\%)\end{array}$ & $95 \% \mathrm{Cl}$ & $\begin{array}{c}\text { PPV } \\
(\%)\end{array}$ & $\begin{array}{l}\text { NPV } \\
(\%)\end{array}$ & $\begin{array}{l}\text { Cut- } \\
\text { off } \\
\text { point }\end{array}$ & $\begin{array}{c}\text { Sens. } \\
(\%)\end{array}$ & $95 \% \mathrm{Cl}$ & $\begin{array}{c}\text { Spec. } \\
(\%)\end{array}$ & $95 \% \mathrm{Cl}$ & $\begin{array}{c}\text { PPV } \\
(\%)\end{array}$ & $\begin{array}{c}\text { NPV } \\
(\%)\end{array}$ \\
\hline \multicolumn{15}{|l|}{ BAI } \\
\hline $8-9$ years & 30.7 & $93 \cdot 1$ & $77 \cdot 2,99 \cdot 0$ & 88.7 & $82 \cdot 9,93 \cdot 0$ & 58.7 & 98.7 & $30 \cdot 1$ & 85.2 & $66 \cdot 3,95 \cdot 7$ & 91.6 & $86 \cdot 0,95 \cdot 4$ & 63.9 & $97 \cdot 2$ \\
\hline $10-11$ years & 28.9 & $88 \cdot 2$ & $63 \cdot 5,98 \cdot 2$ & 88.9 & $80.5,94.5$ & $60 \cdot 0$ & $97 \cdot 6$ & 25.9 & $81 \cdot 3$ & $54 \cdot 3,95 \cdot 7$ & $90 \cdot 4$ & $82 \cdot 6,95.5$ & $59 \cdot 1$ & $96 \cdot 6$ \\
\hline $12-13$ years & $29 \cdot 3$ & $85 \cdot 7$ & $42 \cdot 2,97 \cdot 6$ & $95 \cdot 4$ & $84 \cdot 2,99 \cdot 3$ & $71 \cdot 4$ & $95 \cdot 3$ & $25 \cdot 3$ & $90 \cdot 0$ & $55 \cdot 5,98 \cdot 3$ & 93.2 & $83 \cdot 5,98 \cdot 1$ & $69 \cdot 2$ & $98 \cdot 2$ \\
\hline $14-15$ years & $27 \cdot 6$ & $100 \cdot 0$ & $69 \cdot 0,100 \cdot 0$ & $75 \cdot 8$ & $63 \cdot 3,85 \cdot 8$ & $40 \cdot 0$ & $100 \cdot 0$ & 24.4 & $100 \cdot 0$ & $48.0,100 \cdot 0$ & $97 \cdot 1$ & $85 \cdot 0,99.5$ & $83 \cdot 3$ & $100 \cdot 0$ \\
\hline $16-17$ years & 29.5 & $75 \cdot 0$ & $35 \cdot 0,96 \cdot 1$ & 91.8 & $80 \cdot 4,97 \cdot 7$ & $60 \cdot 0$ & 95.7 & 24.8 & $100 \cdot 0$ & $48 \cdot 0,100 \cdot 0$ & $100 \cdot 0$ & $88 \cdot 7,100 \cdot 0$ & $100 \cdot 0$ & $100 \cdot 0$ \\
\hline $18-19$ years & $29 \cdot 0$ & $80 \cdot 0$ & $44 \cdot 4,96 \cdot 9$ & $91 \cdot 2$ & $80 \cdot 7,97 \cdot 1$ & 61.5 & $96 \cdot 3$ & $21 \cdot 2$ & $100 \cdot 0$ & $69 \cdot 0,100 \cdot 0$ & $66 \cdot 0$ & $51 \cdot 7,78 \cdot 5$ & 35.7 & $100 \cdot 0$ \\
\hline \multicolumn{15}{|c|}{ 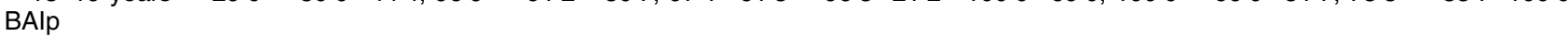 } \\
\hline $8-9$ years & $22 \cdot 6$ & $100 \cdot 0$ & $87 \cdot 9,100 \cdot 0$ & 87.5 & $81 \cdot 5,92 \cdot 1$ & $58 \cdot 0$ & $100 \cdot 0$ & $22 \cdot 1$ & $96 \cdot 3$ & $81 \cdot 0,99 \cdot 4$ & $91 \cdot 6$ & $86 \cdot 0,95 \cdot 4$ & $66 \cdot 7$ & 99.2 \\
\hline $10-11$ years & 20.9 & $100 \cdot 0$ & $80 \cdot 3,100 \cdot 0$ & 80.0 & $70 \cdot 2,87 \cdot 7$ & $48 \cdot 6$ & $100 \cdot 0$ & $17 \cdot 4$ & $100 \cdot 0$ & $79 \cdot 2,100 \cdot 0$ & 79.8 & $70 \cdot 2,87 \cdot 4$ & $45 \cdot 7$ & $100 \cdot 0$ \\
\hline $12-13$ years & $27 \cdot 2$ & $85 \cdot 7$ & $42 \cdot 2,97 \cdot 6$ & $97 \cdot 7$ & $87 \cdot 7,99 \cdot 6$ & 85.7 & $97 \cdot 7$ & $21 \cdot 6$ & $100 \cdot 0$ & $69 \cdot 0,100 \cdot 0$ & 93.2 & $83 \cdot 5,98 \cdot 1$ & 71.4 & $100 \cdot 0$ \\
\hline $14-15$ years & $27 \cdot 8$ & $100 \cdot 0$ & $69 \cdot 0,100 \cdot 0$ & 85.5 & $74 \cdot 2,93 \cdot 1$ & $52 \cdot 6$ & $100 \cdot 0$ & $22 \cdot 3$ & $100 \cdot 0$ & $48 \cdot 0,100 \cdot 0$ & 91.4 & $76 \cdot 9,98 \cdot 1$ & 62.5 & $100 \cdot 0$ \\
\hline $16-17$ years & $25 \cdot 9$ & $100 \cdot 0$ & $62 \cdot 9,100 \cdot 0$ & 69.4 & $54 \cdot 6,81 \cdot 7$ & $34 \cdot 8$ & $100 \cdot 0$ & 24.6 & $100 \cdot 0$ & $48 \cdot 0,100 \cdot 0$ & $100 \cdot 0$ & $88 \cdot 7,100 \cdot 0$ & $100 \cdot 0$ & $100 \cdot 0$ \\
\hline $18-19$ years & $27 \cdot 6$ & $90 \cdot 0$ & $55 \cdot 5,98 \cdot 3$ & 94.7 & $85 \cdot 4,98 \cdot 8$ & $75 \cdot 0$ & $98 \cdot 2$ & $22 \cdot 6$ & $90 \cdot 0$ & $55 \cdot 5,98 \cdot 3$ & 88.7 & $77 \cdot 0,95 \cdot 7$ & $60 \cdot 0$ & $97 \cdot 9$ \\
\hline
\end{tabular}


Table 4 Probabilities of correct decisions and misclassification errors, validity coefficients, and expected utility, disutility and maximal utility for cut-offs points of the body adiposity index (BAl) and the paediatric body adiposity index (BAlp) for the classification of high adiposity, by age and sex, in children and adolescents aged 8-19 years ( $n$ 1049), Viçosa, Minas Gerais, Brazil, 2010-2012/2015

\begin{tabular}{|c|c|c|c|c|c|c|}
\hline \multirow[b]{2}{*}{ Cut-off point } & \multirow[b]{2}{*}{$\begin{array}{c}\text { Probability of correct } \\
\text { decisions }\end{array}$} & \multirow[b]{2}{*}{$\begin{array}{c}\text { Misclassification errors } \\
\text { type I/type II }\end{array}$} & \multirow[b]{2}{*}{$\begin{array}{l}\text { Validity } \\
\text { coefficient }\end{array}$} & \multicolumn{3}{|c|}{ Utility analysis } \\
\hline & & & & $\begin{array}{l}\text { Expected } \\
\text { utility }\end{array}$ & $\begin{array}{l}\text { Expected } \\
\text { disutility }\end{array}$ & $\begin{array}{l}\text { Expected } \\
\text { maximal utility }\end{array}$ \\
\hline \multicolumn{7}{|l|}{ Girls } \\
\hline \multicolumn{7}{|l|}{ BAI } \\
\hline $8-9$ years $(30.7 \%)$ & 0.89 & $0.01 / 0 \cdot 10$ & 0.69 & 1.03 & -0.20 & 163 \\
\hline $10-11$ years $(28.9 \%)$ & 0.87 & $0.04 / 0.09$ & 0.62 & 1.02 & -0.22 & 85 \\
\hline $12-13$ years $(29.3 \%)$ & 0.92 & $0 / 0.08$ & 0.71 & 1.02 & -0.16 & 43 \\
\hline $14-15$ years $(27.6 \%)$ & 0.78 & $0 / 0 \cdot 22$ & 0.53 & 0.92 & -0.44 & 34 \\
\hline $16-17$ years $(29.5 \%)$ & 0.90 & $0.05 / 0.05$ & 0.66 & 1.04 & -0.16 & 50 \\
\hline $18-19$ years $(29.0 \%)$ & 0.90 & $0.02 / 0.09$ & 0.66 & 1.02 & -0.19 & 55 \\
\hline \multicolumn{7}{|l|}{ BAlp } \\
\hline $8-9$ years $(22.6 \%)$ & 0.89 & $0 / 0 \cdot 11$ & 0.70 & 1.04 & -0.22 & 160 \\
\hline $10-11$ years $(20.9 \%)$ & 0.85 & $0 / 0 \cdot 15$ & 0.67 & 1.04 & -0.30 & 79 \\
\hline $12-13$ years $(27.2 \%)$ & 0.96 & $0 / 0.04$ & 0.83 & 1.06 & -0.08 & 49 \\
\hline $14-15$ years $(27.8 \%)$ & 0.86 & $0 / 0.14$ & 0.65 & 1.00 & -0.28 & 52 \\
\hline $16-17$ years $(25.9 \%)$ & 0.79 & $0 / 0.21$ & 0.60 & 0.98 & -0.42 & 32 \\
\hline $18-19$ years $(27.6 \%)$ & 0.90 & $0.02 / 0.09$ & 0.66 & 1.02 & -0.19 & 55 \\
\hline \multicolumn{7}{|l|}{ Boys } \\
\hline \multicolumn{7}{|l|}{ BAI } \\
\hline $8-9$ years $(30 \cdot 1 \%)$ & 0.90 & $0.02 / 0.08$ & 0.67 & 1.03 & -0.18 & 154 \\
\hline $10-11$ years $(25.9 \%)$ & 0.90 & $0.01 / 0.09$ & 0.66 & 1.01 & -0.19 & 90 \\
\hline $12-13$ years $(25.3 \%)$ & 0.93 & $0.03 / 0.04$ & 0.76 & 1.07 & -0.12 & 66 \\
\hline $14-15$ years $(24.4 \%)$ & 0.93 & $0.05 / 0.03$ & 0.76 & 1.08 & $-0 \cdot 10$ & 39 \\
\hline $16-17$ years $(24.8 \%)$ & 0.94 & $0.03 / 0.03$ & 0.80 & 1.08 & -0.08 & 36 \\
\hline $18-19$ years $(21.2 \%)$ & 0.64 & $0 / 0.37$ & 0.37 & 0.75 & -0.73 & 1 \\
\hline \multicolumn{7}{|l|}{ BAlp } \\
\hline $8-9$ years $(22.1 \%)$ & 0.92 & $0.01 / 0.08$ & 0.75 & 1.06 & -0.16 & 163 \\
\hline $10-11$ years $(17.4 \%)$ & 0.80 & $0 / 0 \cdot 20$ & 0.54 & 0.92 & -0.40 & 57 \\
\hline $12-13$ years $(21.6 \%)$ & 0.93 & $0.01 / 0.06$ & 0.78 & 1.09 & -0.13 & 66 \\
\hline $14-15$ years $(22.3 \%)$ & 0.95 & $0.03 / 0.03$ & 0.84 & 1.13 & -0.08 & 42 \\
\hline $16-17$ years $(24.6 \%)$ & 0.94 & $0.03 / 0.03$ & 0.80 & 1.08 & -0.08 & 36 \\
\hline $18-19$ years $(22.6 \%)$ & 0.86 & $0 / 0.14$ & 0.61 & 0.97 & -0.29 & 43 \\
\hline
\end{tabular}

(a)

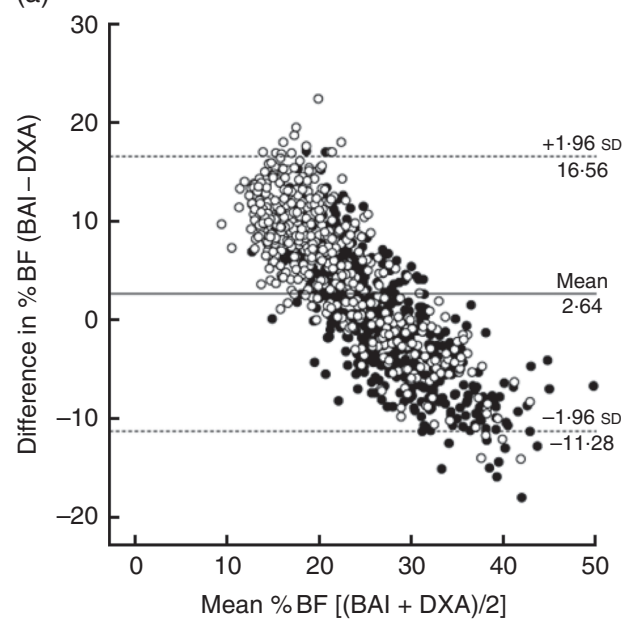

(b)

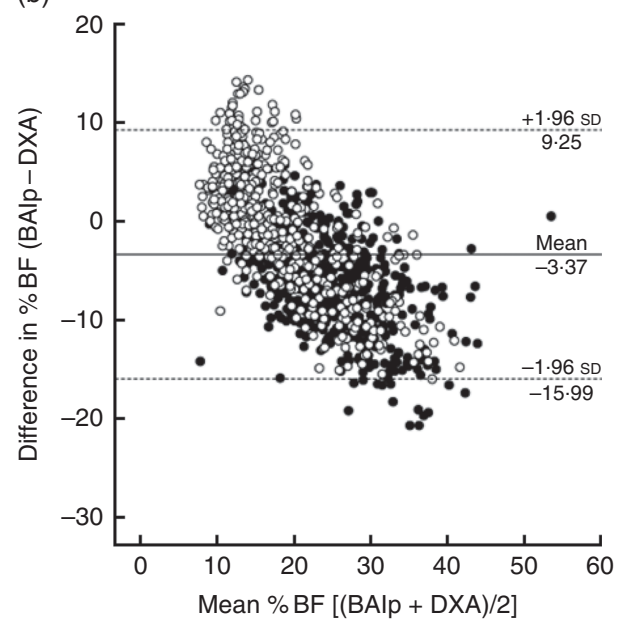

Fig. 1 Bland-Altman's agreement analysis between percentage body fat (\%BF) values estimated by (a) the body adiposity index (BAI) and (b) the paediatric body adiposity index (BAlp) with \%BF values estimated by dual-energy X-ray absorptiometry (DXA), by sex (•, girls; $\circ$, boys), in children and adolescents aged 8-19 years ( $n$ 1049), Viçosa, Minas Gerais, Brazil, 2010-2012/2015. The difference in \%BF between the two methods is plotted $v$. the mean \%BF from the two methods; — represents the mean difference (bias) and - . - represent the limits of agreement

The results of the receiver-operating characteristic curve analysis showed that BAIp and BAI had the ability to predict excess body adiposity in children and adolescents, especially
BAIp, with a better performance in the 18-19 years age group compared with BAI. However, the Bland-Altman test showed no good agreement of these indices with the values 
obtained by DXA, identifying both an overestimation of \%BF by BAI and an underestimation by BAIp.

El Aarbaoui et al. ${ }^{(9)}$ assessed individuals aged 5-12 years to verify the effectiveness of the BAI equation and a possible need for another equation more efficient for the paediatric population. Their results showed that BAI overestimated body fat values in this age group and a paediatric equation was necessary for this evaluation, namely the BAIp.

The predictive capacity observed in the present study possibly reflects the relationship of these indices with the methods of assessing the nutritional status, as confirmed by the literature. In a study with Brazilian adults aged 2059 years, strong correlations were found between the \%BF calculated by BAI and that determined by DXA, with values of 0.72 and 0.78 for men and women, respectively. On the other hand, the authors observed that BAI overestimated the $\% \mathrm{BF}$ in males by $1.01 \%$, while it underestimated by $4.06 \%$ in females ${ }^{(28)}$. Using Cronbach's $\alpha$ and correlation analysis, Dias et $\mathrm{al}^{(7)}$ found a significant correlation between the \%BF values estimated by $\mathrm{BAI}$ and DXA, but the association between the methods using Cronbach's $\alpha$ analysis was only $39 \cdot 3 \%$.

In French adolescents, BAI and BAIp overestimated body fat by more than $3.48 \%$ and $4.62 \%$ in relation to DXA, showing an intraclass correlation coefficient of 0.45 and $0 \cdot 15$, respectively ${ }^{(29)}$. Frignani et $a l^{(30)}$ also evaluated the effectiveness of BAI in evaluating adiposity in adolescents using skinfolds as a reference method. BAI presented associations of 0.71 and 0.68 for boys and girls, respectively, when compared with body fat values determined by skinfolds. In male adolescents, Souza et $a l^{(31)}$ found a correlation of 0.68 between the percentage of fat by BAI and the value estimated by skinfolds.

Similarly to our study, other authors who found correlation and association of BAI and BAIp with the methods considered as reference in the evaluation of body composition also found low agreement, always identifying an over- or underestimation $^{(7,9,28-32)}$.

Dobashi et al. ${ }^{(10)}$ argued that BAIp is a better marker of overweight and body fat in obese children than BAI. One possible explanation for its excellent performance in late adolescence would be that the changes in anthropometric profile and body composition that occur until the end of adolescence are better captured by the equation developed for the paediatric population, which is marked by intense growth and different from the adult stage ${ }^{(10)}$.

Dias et $a l^{(7)}$ used the Bland-Altman residual score analysis and identified that BAI can either overestimate or underestimate the percentage of fat in young women. Colley et $a l .{ }^{(32)}$ analysed the BAI and BAIp equations in relation to the \%BF obtained by DXA in adolescents aged 12-17 years with BMI-for-age values above the 95th percentile and found that both indices underestimated the fat values.
Souza et $\mathrm{al}^{(31)}$ found a good correlation between BAI and \%BF using skinfolds, but the Bland-Altman agreement method again showed that the equation overestimated the values. This low agreement between the BAI and BAIp equations and the body fat values obtained by DXA and skinfolds shows that use of these indices in individuals who are obese or with a high \%BF can lead to errors of over- or underestimation, and should be applied with caution.

We emphasize that the low agreement demonstrated in the Bland-Altman plot was based on the mean difference between measures being significant and the presence of proportional bias. These make it difficult to establish limits of agreement and the possibility of correction of measurements obtained by BAI and BAIp from the mean of differences ${ }^{(25,33)}$

The cut-off points estimated in the present study resulted in higher \%BF by BAI compared with BAIp, regardless of sex. The use of these cut-off points, especially at the outpatient level, should be carefully evaluated, since the positive predictive values were low in some age groups which could result in false positives; that is, diagnose children and adolescents as overweight who do not yet present such alteration in their nutritional status. Besides that, these cut-off points should be associated with other indicators already known and validated for the population, considering that a false diagnosis of overweight or excess body fat can negatively influence the social life of these children and adolescents and can generate unnecessary costs to the health system.

BAI and BAIp showed low agreement with DXA in the estimation of body fat in Brazilian children and adolescents and may lead to errors in the evaluation of \%BF. Therefore, choosing a method for body composition assessment should be done with caution in the paediatric population, both individually and collectively, so that the accuracy of this evaluation can contribute to effective prevention and monitoring of obesity and co-associated morbidities in both current and future life stages. Further studies are needed to evaluate the predictive abilities of BAI and BAIp for excess body adiposity according to reference methods.

\section{Acknowledgements}

Acknowledgements: The authors thank the National Council for Scientific and Technological Development (CNPq) and the Foundation for Research Support of the State of Minas Gerais (FAPEMIG) for the financial support; the Coordination for the Improvement of Higher Education Personnel (CAPES) for granting a scholarship; and the children, adolescents, parents and guardians for participating in the study. Financial support: This work was supported by CNPq (grant numbers 485986/2011-6 and 478910/2013-4) and FAPEMIG (grant number APQ-0161810). CNPq and FAPEMIG had no role in the design, 
analysis or writing of this article. Conflict of interest: The authors declare no conflict of interest. Authorship: M.S.F. assisted the conception and design of this work, assisted the data collection, analysis and interpretation of the data, conducted the literature search, as well as wrote the manuscript. R.S.C., E.R.F. and F.R.F. assisted the conception and design of this work, assisted the data collection, analysis and interpretation, as well as revised and approved the final version to be published. P.F.P. and A.Q.R. revised and approved the final version to be published. S.E.P. and J.F.N. designed the study including the data collection, coordinated and supervised and approved the final version to be published. Ethics of buman subject participation: This study was conducted according to the guidelines laid down in the Declaration of Helsinki and all procedures involving human subjects were approved by the Ethics Committee on Human Research of the Federal University of Viçosa (case numbers 0140/2010 and 663.171/2014). Moreover, this project was presented to the Municipal Department of Education, the Regional Superintendent of Education and principals of schools. All participants, as well as their responsible adults, were informed about the objectives of the research and informed consent was obtained from all children's parents/guardians.

\section{References}

1. World Health Organization (2005) Nutrition in AdolescenceIssues and Challenges for the Health Sector. Issues in Adolescent Health and Development. Geneva: WHO.

2. Oliveira JR, Frutuoso MFP \& Gambardell AMD (2014) Association among sexual maturation, overweight and central adiposity in children and adolescents at two schools in São Paulo. J Hum Growth Dev 24, 201-207.

3. Jaeger AS \& Barón MA (2009) Uso de la bioimpedancia eléctrica para la estimación de la composición corporal en niños y adolescentes. An Venez Nutr 22, 105-110.

4. Kim G \& Caprio S (2011) Diabetes and insulin resistance in pediatric obesity. Pediatr Clin N Am 58, 1355-1361.

5. Oliveira RMS, Franceschini SCC, Rosado GP et al. (2009) Influence of prior nutritional status on the development of the metabolic syndrome in adults. Arq Bras Cardiol 92, 107-112.

6. Instituto Brasileiro de Geografia e Estatística (2010) Pesquisa de Orçamentos Familiares 2008-2009: Antropometria e Estado Nutricional de Crianças, Adolescentes $e$ Adultos no Brasil. Rio de Janeiro: IBGE.

7. Dias J, Ávila M, Damasceno VO et al. (2014) Aplicabilidade do índice adiposidade corporal na estimativa do percentual de gordura de jovens mulheres brasileiras. Rev Bras Med Esporte 20, 17-20.

8. Bergman RN, Stefanovski D, Buchanan TA et al. (2011) A better index of body adiposity. Obesity (Silver Spring) 19, 1083-1089.

9. El Aarbaoui TE, Samouda H, Zitouni D et al. (2013) Does the body adiposity index (BAI) apply to paediatric populations? Ann Hum Biol 40, 451-458.

10. Dobashi K, Takahashi K, Nagahara K et al. (2017) Evaluation of hip/height ${ }^{\mathrm{P}}$ ratio as an index for adiposity and metabolic complications in obese children: comparison with waist-related indices. $J$ Atheroscler Thromb 24, 47-54.
11. Sulino RM, Silva AP, Ramos LE et al. (2011) Comparação entre o índice de adiposidade corporal e a avaliação da composição corporal através de medidas de dobras cutâneas. Col Pesq Educ Fisica 10, 63-68.

12. Instituto Brasileiro de Geografia e Estatística (2010) Censo cidades. http://www.ibge.gov.br/cidadesat/topwindow.htm? 1 (accessed August 2014).

13. Novaes JF, Priore SE, Franceschini SCC et al. (2013) Does the body mass index reflect cardiovascular risk factors in Brazilian children? J Trop Pediatr 59, 43-48.

14. Filgueiras MS, Suhett LG, Silva MA et al. (2018) Lower vitamin D intake is associated with low HDL cholesterol and vitamin D insufficiency/deficiency in Brazilian children. Public Health Nutr 21, 2004-2012.

15. Milagres LC, Rocha NP, Filgueiras MS et al. (2017) Vitamin D insufficiency/deficiency is associated with insulin resistance in Brazilian children, regardless of body fat distribution. Public Health Nutr 20, 2878-2886.

16. Instituto Brasileiro de Geografia e Estatística (2010) Censo demográfico. http://www.cidades.ibge.gov.br/xtras/temas. php?lang $=\&$ codmun $=317130 \&$ idtema $=67 \&$ search $=$ minas geraislvicosalcenso-demografico-2010:-resultados-do-universo caracteristicas-da-populacao-e-dos-domicilios (accessed October 2011).

17. Luiz RR \& Magnanini MMF (2003) O tamanho da amostra em investigações epidemiológicas. In Epidemiologia, pp. 295-307 [RA Medronho, DM Carvalho, KV Block et al., editors]. São Paulo: Atheneu.

18. Faria ER, Faria FR, Franceschini SCC et al. (2014) Resistência à insulina e componentes da síndrome metabólica, análise por sexo e por fase da adolescência. Arq Bras Endocrinol Metab 58, 610-618.

19. Pereira PF, Faria FR, Faria ER et al. (2015) Anthropometric indices to identify metabolic syndrome and hypertriglyceridemic waist phenotype: a comparison between the three stages of adolescence. Rev Paul Pediatr 33, 194-203.

20. Lohman T (1988) Anthropometric Standardization Reference Manual. Champaign, IL: Human Kinetics Books.

21. World Health Organization (2007) Growth Reference Data for 5-19 Years. Geneva: WHO.

22. McCarthy HD, Cole TJ, Fry T et al. (2006) Body fat reference curves for children. Int J Obes (Lond) 30, 598-602.

23. Flegal KM, Ogden CL, Yanovski JA et al. (2010) High adiposity and high body mass index-for-age in US children and adolescents overall and by race-ethnic group. Am J Clin Nutr 91, 1020-1026.

24. Berk RA (1976) Determination of optional cutting scores in criterion-referenced measurement. $J$ Exp Educ $\mathbf{4 5}$, 4-9.

25. Bland JM \& Altman DG (1986) Statistical methods for assessing agreement between two methods of clinical measurement. Lancet 1, 307-310.

26. Monaghan K, Delahunt E \& Caulfield B (2007) Increasing the number of gait trial recordings maximises intra-rater reliability of the CODA motion analysis system. Gait Posture 25, 303-315.

27. Souza WC, Tajes Junior D, Mascarenha LPG et al. (2015) Índice de adiposidade corporal (IAC) como preditor de gordura corporal: um estudo de revisão. Saude Meio Ambient 4, 32-38.

28. Segheto W, Coelho FA, Silva DCG et al. (2017) Validity of body adiposity index in predicting body fat in Brazilians adults. Am J Hum Biol 29, e22901.

29. Thivel D, O'Malley G, Pereira B et al. (2015) Comparison of total body and abdominal adiposity indexes to dual X-ray absorptiometry scan in obese adolescents. Am J Hum Biol 27, 334-338.

30. Frignani RR, Passos MAZ, Ferrari GLM et al. (2015) Reference curves of the body fat index in adolescents and their 
association with anthropometric variables. J Pediatr (Rio J) 91, 248-255.

31. Souza WC, Grzelczak T, Alarcón-Meza EI et al. (2016) Aplicabilidade do índice de adiposidade corporal na estimativa da gordura corporal em escolares masculino. RBONE 10, 12-19.
32. Colley D, Cines B, Current N et al. (2015) Assessing body fatness in obese adolescents: alternative methods to dualenergy x-ray absorptiometry. Digest (Wash D C) 50, 1-7.

33. Bland JM \& Altman DG (1999) Measuring agreement in method comparison studies. Stat Methods Med Res 8, 135-160. 